\title{
Photosynthesis performance in sweet almond [Prunus dulcis (Mill) D. Webb] exposed to supplemental UV-B radiation
}

\author{
A. RANJBARFORDOEI ${ }^{*,}$, R. SAMSON**, and P. VAN DAMME*** \\ Department of Natural Resources, Shahrekord University P.O. Box 115, Shahrekord, Iran* \\ Department of Bioscience Engineering, Research Group of Plant Production and Stress Tolerance, University of \\ Antwerp, Groenenborgerlaan 171, 2020 Antwerpen, Belgium** \\ Department of Plant Production, Laboratory of Tropical and Subtropical Plants, Ghent University-UGent, Coupure \\ links 653, 9000 Gent, Belgium***
}

\begin{abstract}
Due to anthropogenic influences, solar UV-B irradiance at the earth's surface is increasing. To determine the effects of enhanced UV-B radiation on photosynthetic characteristics of Prunus dulcis, two-year-old seedlings of the species were submitted to four levels of UV-B stress, namely $0\left(U V-B_{c}\right), 4.42\left(U V-B_{1}\right), 7.32\left(U V-B_{2}\right)$ and $9.36\left(U V-B_{3}\right) k^{-2} m^{-2} \mathrm{~d}^{-1}$. Effects of UV-B stress on a range of chlorophyll (Chl) fluorescence parameters (FPs), Chl contents and photosynthetic gas-exchange parameters were investigated. UV-B stress promoted an increase in minimal fluorescence of dark-adapted state $\left(\mathrm{F}_{0}\right)$ and $\mathrm{F}_{0} / \mathrm{F}_{\mathrm{m}}$, and a decrease in variable fluorescence $\left(\mathrm{F}_{\mathrm{v}}, \mathrm{F}_{\mathrm{v}} / \mathrm{F}_{\mathrm{m}}, \mathrm{F}_{\mathrm{v}} / \mathrm{F}_{0}\right.$ and $\left.\mathrm{F}_{0} / \mathrm{F}_{\mathrm{m}}\right)$ due to its adverse effects on photosystem II activity. No significant change was observed for maximal fluorescence of dark-adapted state $\left(\mathrm{F}_{\mathrm{m}}\right)$. Enhanced UV-B radiation caused a significant inhibition of net photosynthetic rate $\left(P_{\mathrm{N}}\right)$ at UV- $\mathrm{B}_{2}$ and $\mathrm{UV}-\mathrm{B}_{3}$ levels and this was accompanied by a reduction in stomatal conductance $\left(g_{\mathrm{s}}\right)$ and transpiration rate $(E)$. The contents of Chl $a, b$, and total Chl content $(a+b)$ were also significantly reduced at increased UV-B stress. In general, adverse UV-B effects became significant at the highest tested radiation dose $9.36 \mathrm{~kJ} \mathrm{~m}^{-2} \mathrm{~d}^{-1}$. The most sensitive indicators for UV-B stress were $\mathrm{F}_{\mathrm{v}} / \mathrm{F}_{0}$, Chl $a$ content and $P_{\mathrm{N}}$. Significant $P<0.05$ alteration in these parameters was found indicating the drastic effect of UV-B radiation on $P$. dulcis.
\end{abstract}

Additional key words: chlorophyll content, fluorescence quenching, photosystem.

\section{Introduction}

Plants are exposed to a multitude of natural biotic and abiotic stressors. Almost all stressors affect either directly or indirectly the photosynthetic performance of leaves (Lichtenthaler and Babani 2000). Differences in photosynthetic rates are most likely to be observed under conditions of environmental stress (Earl and Tollenaar 1999), like e.g. drought (Rouhi et al. 2007) and salinity (Ranjbarfordoei et al. 2006). Most of the abiotic stresses are connected to anthropogenic activities which are clearly causing major changes in atmospheric chemistry and climate (Reddy et al. 2004). The anthropogenic destruction of earth's stratospheric protective ozone layer is of concern because the ozone column is the primary attenuator of solar UV-B radiation $(280-320 \mathrm{~nm})$. Reduction of the ozone layer has led to a substantial increase in
UV-B radiation at the earth's surface, with the amount and intensity dependent on atmospheric and geographic factors (Madronich et al. 1998, Balakrishnan et al. 2005). Several studies have indicated that supplemental UV-B radiation can deleteriously affect plant physiological processes (Rathore et al. 2003). However, Musil et al. (2003) reported that photosynthesis of Podalyria calyptrate was unaffected by enhanced UV-B. Supplementation of PAR radiation with UV-B radiation causes a reduction in $\mathrm{Chl}$ content (Mészáros et al. 2005), photosynthetic $\mathrm{CO}_{2}$ assimilation, and photosynthetic efficiency (Xiaoqin et al. 2008). Furthermore, it has been reported that photosystem II is often snsitive to UV-B radiation and has often been assumed to be the most sensitive photosynthetic target for UV-B (Melise et al.1992). In Iran, but also in other places

Received 22 May 2009, accepted 25 January 2011.

${ }^{+}$Corresponding author; fax: +98 381 4424428, e-mail: Ranjbar@agr.sku.ac.ir

Abbreviations: CA - cellulose diacetate; Chl $a(b)$ - chlorophyll $a(b)$; Chl FY - chlorophyll fluorescence yield; DAS - dark-adapted state; $E$ - transpiration rate; $\mathrm{F}_{\mathrm{m}}$ - maximal fluorescence of dark-adapted state; $\mathrm{F}_{\mathrm{v}}$ - variable fluorescence; $\mathrm{F}_{0}-$ minimal fluorescence of dark-adapted state; FM - fresh mass; FPs - chlorophyll fluorescence parameters; $g_{\mathrm{s}}-$ stomatal conductance; $P_{\mathrm{N}}-$ net photosynthetic rate; PAR - photosynthetically active radiation; PSII - photosystem II; UV-B - ultraviolet-B radiation. 
worldwide, orchard crops such as almond, walnut, hazelnut and grapes are mainly confined to mountain regions and higher altitudes. At higher altitudes, more UV-B can reach the earth's surface, because the atmosphere tends to be cleaner and less dense than at lower elevations. In general, each $\mathrm{km}$ increase in altitude increases the ultraviolet flux by about 6\% (Diffey 1991).

Plant species vary greatly in their response to UV-B. Long-lived trees such as almond must be the most

\section{Materials and methods}

Plants: Two-year-old almond seedlings [Prunus dulcis (Mill) D.A. Webb], of a height of $1.2 \mathrm{~m}$, were purchased from an almond nursery in Saman city (situated in the province of Chaharmahal-Bakhtiary, Iran). Seedlings were brought to a glasshouse located at Shahrekord University in late March 2008 and were transferred, with the least root disturbance, to $6,000 \mathrm{~cm}^{3}$ plastic pots filled with a mixture of local sifted soil, sand and farm yard manure in the proportion of $2: 2: 1(\mathrm{v} / \mathrm{v} / \mathrm{v})$. Plants were kept in the glasshouse with mean daily minimum and maximum air temperature of $25-38^{\circ} \mathrm{C}$, respectively. Relative humidity of the air was around $50 \%$, and plants were subjected to the natural photoperiod till the end of July. In order to maintain constant soil moisture, the plants were uniformly watered throughout the experiment twice a day using a circulating system consisting of a water pump, gutter, and water reservoir. Each time the pumps were switched on for 30 min (early in the morning and late in the afternoon). A total of 20 almond plants, i.e., five plants per treatment, were used in this experiment, each plant serving as an experimental unit.

UV-B treatments: In early August 2008, the seedlings were exposed to the UV-B treatments. UV-B radiation was artificially supplied by $36 \mathrm{~W}$ fluorescent lamps (UV-B, Zhejiang Yongkang Yongxin Industry Co., China) following the procedure described by Lydon et al. (1986). The lamps were suspended above and perpendicular to the pots and wrapped with $0.13 \mathrm{~mm}$ cellulose diacetate (CA) film to cut off UV-C radiation shorter than $290 \mathrm{~nm}$. The CA filter on the lamps was replaced weekly to avoid photodegradation of CA properties caused by UV-B radiation. The spectral irradiance from the lamps was determined with a UV spectroradiometer (MSS2040, MSS - Electronic GmbH, Germany). The generalized plant action spectrum (Caldwell 1971), normalized at $300 \mathrm{~nm}$, was used in accordance with the methods mentioned by Correia et al. (2005). Four levels of UV-B irradiation of $0,4.42,7.32$, and $9.36 \mathrm{~kJ} \mathrm{~m}^{-2} \mathrm{~d}^{-1}\left(\mathrm{UV}-\mathrm{B}_{\mathrm{c}}\right.$ to $\mathrm{UV}-\mathrm{B}_{3}$, respectively) were used for $6 \mathrm{~h}$ at the middle of the photoperiod (daily from 10:00 to $16: 00 \mathrm{~h}$ of the local time).

Gas-exchange measurements: $P_{\mathrm{N}}, g_{\mathrm{s}}$, and $E$ were measured after 5 weeks of UV-B radiation on fully expanded leaves (fourth leaf from the apex). Measure- impacted by the permanent exposure and accumulation of the effects (Láposi et al. 2005). Although almond is an important orchard crop in Iran and many other countries, few experiments have addressed the influence of UV-B radiation on this tree. Therefore, the present study aims to clarify the effects of UV-B stress on seedlings of $P$. dulcis based on leaf photosynthesis as measured by means of Chl fluorescence, gas exchange and $\mathrm{Chl}$ content.

ments were made inside the glasshouse at photosynthetically active radiation (PAR, natural light) of $1,400 \pm$ $70 \mu \mathrm{mol} \mathrm{m} \mathrm{m}^{-2} \mathrm{~s}^{-1}$, air temperature of $36 \pm 1.5^{\circ} \mathrm{C}$ and $55 \%$ RH. All measurements were carried out around midday (from 11:00 to 13:00 $\mathrm{h}$ of the local time) using a portable photosynthesis system (LCA-3, ADC BioScientific Ltd., Hoddesdon, UK)). Atmospheric $\mathrm{CO}_{2}$ concentration in the cuvette was fixed at $380 \mu \mathrm{mol} \mathrm{mol}{ }^{-1}$, and PAR intensity at $1350 \pm 50 \mu \mathrm{mol} \mathrm{m} \mathrm{s}^{-2} . P_{\mathrm{N}}, g_{\mathrm{s}}$ and $E$ were calculated using the equations described by von Caemmerer and Farquhar (1981). The measurements were done in the absence of UV-B to avoid instantaneous effects of the $\mathrm{UV}-\mathrm{B}$ radiation.

Chl fluorescence: Chl $a$ fluorescence parameters (FPS) were measured with a portable fluorometer (PAM-2000, Walz $G m b H$, Effeltrich, Germany) on the same leaves as used for gas-exchange determination. Prior to the measurements, leaves were kept in dark-adapted state (DAS) for $30 \mathrm{~min}$ (Genty et al. 1989) using light exclusion clips for dark adaptation. During DAS all reaction centers and electron carriers of the PSII are reoxidized; this situation is essential for rapid fluorescence induction kinetics and, for recording Chl FPs. The intensity of the saturation pulse was $4,000 \mu \mathrm{mol} \mathrm{m} \mathrm{m}^{-2} \mathrm{~s}^{-1}$ PAR with a duration of $800 \mathrm{~ms}$.

The following Chl fluorescence yields (Chl FYs) were measured: minimum and maximum $\mathrm{Chl} F Y$ in darkadapted state $\left(\mathrm{F}_{0)}\right.$ and $\left(\mathrm{F}_{\mathrm{m}}\right)$, respectively. Based on these Chl FYs, some Chl FPs such as variable fluorescence $\left(\mathrm{F}_{\mathrm{v}}\right)$, (the difference between $\mathrm{F}_{0}$ and $\mathrm{F}_{\mathrm{m}}$ ), maximum quantum yield of photosynthesis $\left(\mathrm{F}_{\mathrm{v}} / \mathrm{F}_{\mathrm{m}}\right), \mathrm{F}_{\mathrm{v}} / \mathrm{F}_{0}$ and basal quantum yield of non-photochemical processes in PSII $\left(\mathrm{F}_{0} / \mathrm{F}_{\mathrm{m}}\right)$ were calculated (Ranjbarfordoei et al. 2006).

Chl content: After gas-exchange and Chl fluorescence measurements, two leaves (the same leaf as used for gas exchange and Chl fluorescence, and the leaf closest to that one) were collected from each plant. Leaves were immediately wrapped in aluminum foil to avoid degradation of pigments by light. Soon afterwards, $0.5 \mathrm{~g}$ samples were taken from the collected leaves. These samples were then pulverized with liquid nitrogen. Subsequently, $0.25 \mathrm{~g}$ of each sample was extracted by $80 \%$ acetone and put in the freezer at $-5^{\circ} \mathrm{C}$ for $24 \mathrm{~h}$. 
Pigments were determined according to Lichtenthaler (1987) using a spectrophotometer (Uvikon 930, Kontron

\section{Results}

The results in Fig. 1 show the effects of enhanced UV-B radiation on net photosynthetic rates in fully expanded leaves at different UV-B intensities. Maximum photosynthetic rate was observed at $\mathrm{UV}-\mathrm{B}_{1}$ and $\mathrm{UV}-\mathrm{B}_{\mathrm{C}}$ (control level) and then declined significantly from UV-B $\mathrm{B}_{2}$. Net photosynthetic rate decreased by average $28 \%$ in UV-B treated plants compared to the control, and this effect was accompanied by decreases in $g_{\mathrm{s}}(41.8 \%)$ and $E(20.6 \%)$ (Fig. 1).

Exposure of almond plants to the selected UV-B doses induced remarkable alterations in FYs (Table 1). Five weeks of UV-B irradiation significantly affected $F_{0}$ which showed an increase for $U V-B_{2}$ and $U V-B_{3}$, but no significant difference was observed between $U V-B_{c}$ and, $U V-B_{1}$. A reduction in $F_{v}$, and $F_{v} / F_{m}$, was observed with increasing UV-B intensities, but only UV-B $B_{2}$ and $U V-B_{3}$ levels were significantly different from $U V-B_{c}$.

UV-B treatment decreased the $\mathrm{F}_{\mathrm{v}} / \mathrm{F}_{0}$ ratio with about $21 \% . \mathrm{F}_{0} / \mathrm{F}_{\mathrm{m}}$ did not change significantly with increasing $U V-B$ intensities from $U V-B_{c}$ to $U V-B_{1}$, but a further increase led to a significant increase of the parameter from about 0.191 at $\mathrm{UV}-\mathrm{B}_{1}$ to 0.235 at $\mathrm{UV}-\mathrm{B}_{3}$. $\mathrm{F}_{\mathrm{m}}$ was not affected by the UV-B radiation treatments and remained constant (Table 1 ).

$\mathrm{UV}-\mathrm{B}$ radiation caused a significant reduction in $\mathrm{Chl}$ $a$ when the intensity exceeded UV-B ${ }_{2}$ (Table 1). The size of reduction varied ranging from a reduction by $15 \%$ in $\mathrm{UV}-\mathrm{B}_{2}$ to a reduction by $24 \%$ in UV- $\mathrm{B}_{3}$ compared to UV$\mathrm{B}_{\mathrm{c}}$, respectively. A similar decreasing trend was also observed for Chl $b$, but the reduction of Chl $a$ was somewhat greater than reduction in $\mathrm{Chl} b$. At all treatments, UV-B radiation induced a reduction in total Chl $(a+b)$, but a significant reduction was initiated at $\mathrm{UV}-\mathrm{B}_{2}$ and was more pronounced at $\mathrm{UV}-\mathrm{B}_{3}$. In contrast, UV-B enrichment did not result in a significant alteration in the ratio of $\mathrm{Chl} a / b$ (Table 1 ).

\section{Discussion}

Exposure of almond seedlings to increased UV-B radiation negatively and significantly affected the process of photosynthesis including $\mathrm{CO}_{2}$ assimilation $\left(P_{\mathrm{N}}\right)$, stomatal conductance to water vapour $\left(g_{\mathrm{s}}\right)$ and transpiration rate $(E)$. Several studies have confirmed the deleterious effects of UV-B radiation on photosynthetic processes (Keiller and Holmes 2001, Mészáros et al. 2001, Correia et al. 2005, Mészáros et al. 2005, Láposi et al. 2005, Cechin et al. 2007) but less is known about the way how
Instruments, Watford, UK). Amounts of Chl $a$ and $b$ were calculated according to Welburn (1994).

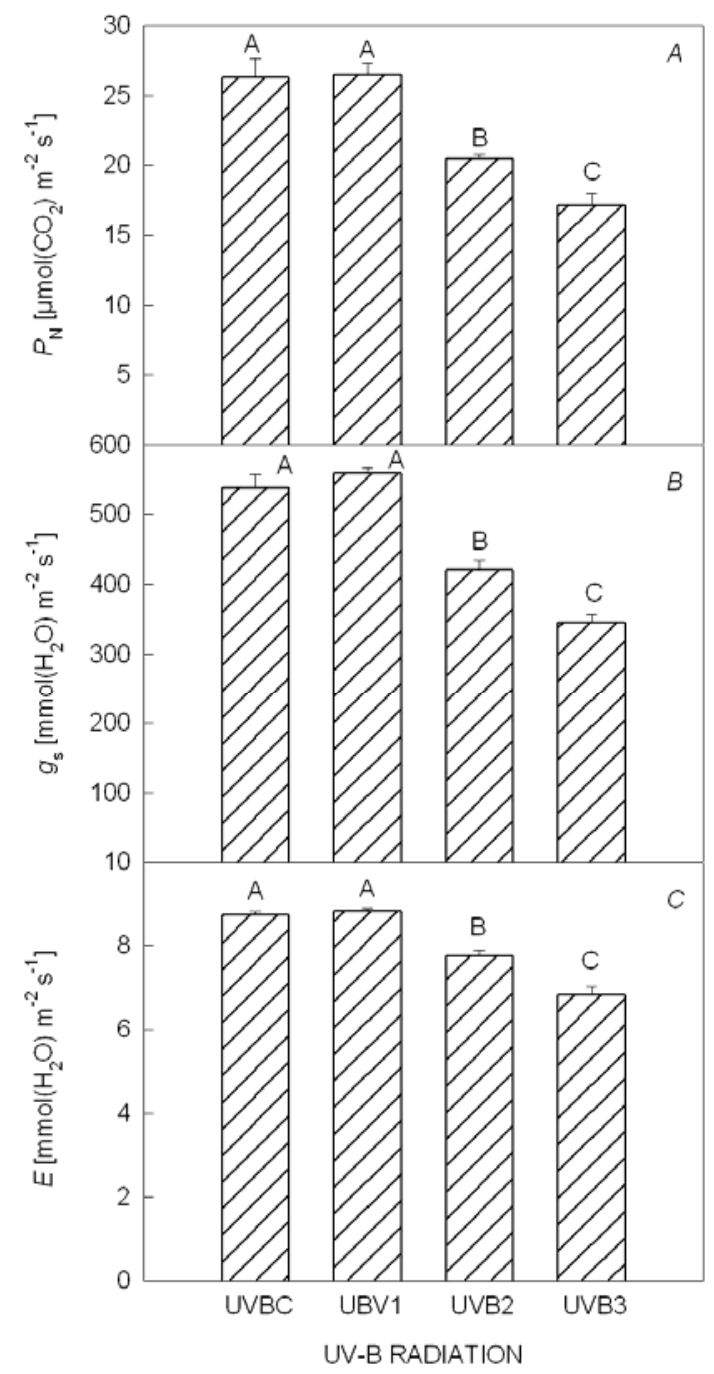

Fig. 1. Changes in the rates of $\mathrm{CO}_{2}$ assimilation $\left(P_{\mathrm{N}}\right)$, stomatal conductance $\left(g_{\mathrm{s}}\right)$ and transpiration $(E)$ in Prunus dulcis seedlings exposed to different intensities of UV-B radiation. Different letters express significant differences between treatments at $P<0.05$. Data are mean values $\pm \mathrm{SE}(n=5)$.

UV-B radiation affects photosynthetic activity in almond plants. The significant reduction in $P_{\mathrm{N}}$ suggests that UV-B treatment can affect photosynthesis by affecting enzyme activity, primary photochemistry, electron transport, biochemical reactions of the Calvin cycle, as well as changes in the structure of the chloroplasts (Borman 1989, Ambasht and Agrawal 1995, Balakrishnan et al. 2005, Cechin at al. 2007). In the present study, fluorescence measurements show an 
Table 1. Chlorophyll (Chl) fluorescence parameters and $\mathrm{Chl} a$ and $b$ content $\left[\mathrm{mg} \mathrm{g}^{-1}(\mathrm{FM})\right.$ in Prunus dulcis at control and three increasing UV-B doses $\left(U V-B_{C}: 0, U V-B_{1}: 4.42, U V-B_{2}: 7.32\right.$ and $U V-B_{3}: 9.36 \mathrm{~kJ} \mathrm{~m}^{-2} \mathrm{~d}^{-1}$ ). Different letters express significant difference between treatments $(P<0.05)$.

\begin{tabular}{lllll}
\hline Parameter & $\begin{array}{l}\text { UV-B treatment } \\
\text { UV-B }_{C}\end{array}$ & UV-B $_{1}$ & UV-B & \\
& $2.04 \pm 0.09^{\mathrm{a}}$ & $1.95 \pm 0.01^{\mathrm{a}}$ & $1.37 \pm 0.04^{\mathrm{b}}$ & UV-B $_{3}$ \\
\hline $\mathrm{Chl} a$ & $0.61 \pm 0.01^{\mathrm{a}}$ & $0.60 \pm 0.02^{\mathrm{a}}$ & $0.53 \pm 0.01^{\mathrm{b}}$ & $0.47 \pm 0.03^{\mathrm{bc}}$ \\
$\mathrm{Chl} b$ & $2.66 \pm 0.02^{\mathrm{a}}$ & $2.54 \pm 0.05^{\mathrm{a}}$ & $2.26 \pm 0.07^{\mathrm{b}}$ & $2.02 \pm 0.049^{\mathrm{c}}$ \\
$\mathrm{Chl}(a+b)$ & $3.37 \pm 0.16^{\mathrm{a}}$ & $3.30 \pm 0.10^{\mathrm{a}}$ & $3.27 \pm 0.02^{\mathrm{a}}$ & $3.34 \pm 0.14^{\mathrm{a}}$ \\
$\mathrm{Chl} a / b$ & $0.168 \pm 0.003^{\mathrm{a}}$ & $0.166 \pm 0.004^{\mathrm{a}}$ & $0.196 \pm 0.005^{\mathrm{b}}$ & $0.198 \pm 0.006^{\mathrm{b}}$ \\
$\mathrm{F}_{0}$ & $0.870 \pm 0.006^{\mathrm{a}}$ & $0.896 \pm 0.006^{\mathrm{a}}$ & $0.827 \pm 0.004^{\mathrm{b}}$ & $0.818 \pm 0.005^{\mathrm{abc}}$ \\
$\mathrm{F}_{\mathrm{m}}$ & $0.705 \pm 0.007^{\mathrm{a}}$ & $0.702 \pm 0.009^{\mathrm{a}}$ & $0.631 \pm 0.008^{\mathrm{ab}}$ & $0.0619 \pm 0.007^{\mathrm{abc}}$ \\
$\mathrm{F}_{\mathrm{v}}$ & $0.806 \pm 0.004^{\mathrm{a}}$ & $0.807 \pm 0.006^{\mathrm{a}}$ & $0.752 \pm 0.010^{\mathrm{ab}}$ & $0.757 \pm 0.007^{\mathrm{ab}}$ \\
$\mathrm{F}_{\mathrm{v}} / \mathrm{F}_{\mathrm{m}}$ & $0.193 \pm 0.004^{\mathrm{a}}$ & $0.191 \pm 0.006^{\mathrm{a}}$ & $0.237 \pm 007^{\mathrm{b}}$ & $0.242 \pm 0.007^{\mathrm{ab}}$ \\
$\mathrm{F}_{0} / \mathrm{F}_{\mathrm{m}}$ & $4.183 \pm 0.010^{\mathrm{a}}$ & $4.237 \pm 0.174^{\mathrm{a}}$ & $3.231 \pm 0.122^{\mathrm{b}}$ & $3.140 \pm 0.125^{\mathrm{b}}$ \\
$\mathrm{F}_{\mathrm{v}} / \mathrm{F}_{0}$ & & & & \\
\hline
\end{tabular}

increase in $\mathrm{F}_{0}$ which indicates the impairment of the lightharvesting complex of PSII (Krause and Weis 1991). On the other hand our data indicate that almond leaves exposed to UV-B radiation exhibited no significant changes in $\mathrm{F}_{\mathrm{m}}$ level, which suggests the secondary electron acceptor of PSII was not probably damaged. Significant reduction of $F_{v}$ indicates a reduction rate of quencher $\mathrm{Q}_{\mathrm{A}}$ and a decrease in PSII quantum yield (Fernandez et al. 1997). Efficiency and stability of PSII, the major component of the photosynthetic apparatus, was monitored during the experiment by means of $\mathrm{F}_{\mathrm{v}} / \mathrm{F}_{\mathrm{m}}$. Alteration in $\mathrm{F}_{\mathrm{v}} / \mathrm{F}_{\mathrm{m}}$ implies changes in photochemical conversion efficiency of PSII and, therefore, possible photoinhibition of photosynthesis. Under nonstressed conditions, $\mathrm{F}_{\mathrm{v}} / \mathrm{F}_{\mathrm{m}}$ is almost constant (from 0.80 to 0.86 ) (Björkman and Demming 1987). Our most severe UV-B treatment decreased $F_{v} / F_{m}$ to $0.7572 \pm 0.016$. This reduction provides clear proof for thermal dissipation processes (Scarascia Mugnozza et al. 1996). The principal cause of increase in $\mathrm{F}_{0} / \mathrm{F}_{\mathrm{m}}$ (induced by UV-B radiation) can be attributed to a loss of excitation energy during its transfer from the pigment bed to the RCs and to an increase of energy loss through nonphotochemical

\section{References}

Ambasht, N.K., Agrawal, M.: Physiological responses of field growth Zea mays L. plants to enhanced UV-B radiation. Biotronics 24: 15-23, 1995.

Balakrishnan, V., Ravindran, K.C., Venkatesan, K., Karuppusamy, S.: Effects of UV-B supplemental radiation on growth and biochemical characteristics in Crotalaria junea L. seedlings. - Electron. J. Environ. Agric. Food Chem. 4: 1125$1131,2005$.

Björkman, O., Demming, B.: Photon yield of $\mathrm{O}_{2}$ evolution and chlorophyll fluorescence characteristics at $77 \mathrm{~K}$ among vascular plants of diverse origins. - Planta 170: 489-504, 1987.

Bornman, J.F.: Target sites of UV-B in photosynthesis of higher plants. - J. Photochem. Photobiol. B: Biol. 84: 145-158, 1989.

Caldwell, M.M.: Solar Ultraviolet radiation and the growth and development of higher plants. - In: Gies, A.C. (ed.): Photo- quenching processes (Roháček 2002).

UV-B exposure of $P$. dulcis plants led to a substantial reduction in the content of both Chls $a$ and $b$, which reveals a possible damage in the photosynthetic capacity of chloroplasts (Kakani et al. 2004). Mackerness et al. (1999) suggested that under UV-B stress, plants sacrifice their chloroplasts in order to protect the rest of the cell. UV-B radiation might affect the photosynthetic pigments, either through inhibition of their synthesis or effects on the enzymes involved in the Chl biosynthetic pathway. In the UV-B stressed almond plants, the decrease in Chl $a$, $\mathrm{Chl} b$, and $\mathrm{Chl}(a+b)$, suggests a possible damage of the light-harvesting complex. Similar responses were observed in Sinapsis alba (Jennifer et al. 2000) and Helianthus annuus L. (Cechin et al. 2007) plants.

Conclusion: The present investigation showed that supplemental UV-B radiation caused adverse effects on activity of photosystem II in almond seedlings leading to reductions in photosynthetic gas exchange and $\mathrm{Chl}$ pigments. Parameters such as $\mathrm{F}_{\mathrm{v}} / \mathrm{F}_{0}, \mathrm{Chl} a$ content and $P_{\mathrm{N}}$ were useful indicators of the plant's response to UV-B.

physiology. Pp. 131-177. Academic Press, New York 1971.

Cechin, I., Fumis, T. de F., Dokkedal, A.L.: Growth and physiological response of sunflower exposed to UV-B radiation. - Ciência Rural 37: 85-90, 2007.

Correia, C.M., Pereira, J.M.M., Coutinho, J.F., Björn, L.O., Torres-Pereira, J.M.G.: Ultraviolet-B radiation and nitrogen affect the photosynthesis of maize: a Mediterranean field study. - Eur. J. Agron. 22: 337-347, 2005.

Diffey, B. L.: Solar ultraviolet radiation effects on biological systems. - Rev. Phys. Med. Biol. 36: 299-328, 1991.

Earl, H.J., Tollenaar, M.: Using chlorophyll fluorometry to compare photosynthetic performance of commercial maize (Zea mays L.) hybrids in the field. - Field Crops Res. 61: 201210, 1999.

Fernandez, R.T., Perry, R.L., Flore, J.A.: Drought response of 
young apple trees on three rootstocks. II Gas exchange, chlorophyll fluorescence, water relations, and leaf abscisic acid. - J. Amer. Soc. Hort. Sci. 122: 841-848, 1997.

Genty, B., Briantais, J.M., Baker, N.R.: The relationship between the quantum yield of photosynthetic electrontransport and quenching of chlorophyll fluorescence. Biochim. Biophys. Acta 990: 87-92, 1989.

Kakani, V.G., Reddy, K.R., Zhao, D., Gao, W.: Senescence and hyperspectral reflectance of cotton leaves exposed to ultaviolet-B radiation and carbon dioxide. - Physiol. Plant. 121:250-257, 2004.

Keiller, D.R., Holmes, M.G.: Effects of long-term exposure to elevated UV-B radiation on the photosynthetic performance of five broad leaved tree species. - Photosynth. Res. 67: 229240, 2001

Krause, G.H., Weis, E.: Chlorophyll fluorescence and photosynthesis: The basics. - Annu. Rev. Plant Physiol. Biol. 42: 313-349, 1991.

Láposi, R., Veres, S., Mile, O., Mészáros, I.: Effects of supplemental UV-B radiation on the photosynthesis, physiological properties and flavonoid content of beech seedlings (Fagus sylvatica L.) in outdoor conditions. - Acta Biol. Szegediensis 49: 151-153, 2005.

Lichthentaler, H.K., Chlorophyll and carotenoids - pigments of photosynthetic biomembranes, - In: Colowick, S.P., Kaplan, N.O. (ed.): Methods in Enzymology, Vol. 148, Pp 350-382. Academic Press, San Diego - New York - Berkeley - Boston - London - Sydney - Tokyo - Toronto 1987.

Lichtenthaler, H.K., Babani, F.: Detection of photosynthetic activity and water stress by imaging the red chlorophyll fluorescence. - Plant Physiol. Biochem. 38: 889-895, 2000.

Lydon, J., Teramura, A.H., summers, E.G.: Effects of ultraviolet-B radiation on growth and productivity of field grown soybean. - In: Worrest, R.C., Caldwell, M.M. (ed.): Stratospheric Ozone Reduction, Solar Ultraviolet Radiation and Plant Life. Pp.313-325. Springer-Verlag, Berlin Heidelberg - New York - Tokyo 1986.

Mackerness, S.A., Jordan, B.R., Thomas B.: Reactive oxygen species in the regulation of photosynthetic genes by ultraviolet-B radiation (UV-B: $280-320 \mathrm{~nm}$ ) in green and etiolated buds of pea (Pisum sativum L.). - J. Photochem. Photobiol. 84: 180-188, 1999.

Madronich, S., McKenzie, R.L., Björn, L.O., Caldwell, M.M.: Changes in biologically active ultraviolet radiation reaching the Earth's surface. - J. Photochem. Photobiol. B:Biol. 46: 519, 1998.

Mészáros, I., Láposi, R., Veres, S., Bai, E., Lakatos, G., Cáspár, A., Mile, O.: Effects of supplemental UV-B and drought stress on photosynthetic activity of sessile oak (Quercus petraea L.). - Proc. of $12^{\text {th }}$ International Congress on Photosynthesis. Pp. 34-34. CSIRO Publ., Collingwood 2001.

Mészáros, I., Láposi, R., Veres, S., Sárvári, É., Gáspár, A., Bai, E., Oláh, V., Lakatos, G.: Effects of supplemental UV-B radiation on photosynthesis performance and UV-B absorbing compounds in leaves of two oak species. - Acta Biol.
Szegediensis 49:165-66, 2005.

Melis, A., Nemson, J.A., Harrison M.A.: Damage to functional components and partial degradation of Photosystem II reaction center proteins upon chloroplast exposure to ultraviolet-B radiation. - Biochim. Biophys. Acta 1100: 312320, 1992.

Musil, C.F., Kgope, B.S., Chimphango, S.B.M., Dakora, FD.: Nitrate additions enhance the photosynthetic sensitivity of a nodulated South African Mediterranean-climate legume (Podalyria calyptrate) to elevated UV-B. - Environ. Exp. Bot. 50: 197-210, 2003.

Ranjbarfordoei, A., Samson, R., Lemeur, R., Van Damme, P.: Effects of osmotic stress induced by a combination of $\mathrm{NaCl}$ and polyethylene glycol on leaf water status, photosynthetic gas exchange, and water use efficiency of Pistacia khinjuk and P. mutica. - Photosynthetica 40: 165-169, 2002.

Ranjbarfordoei, A., Samson, R., Van Damme, P., Chlorophyll fluorescence performance of sweet almond [Prunus dulcis (Miller) D. Webb] in response to salinity stress induced by NaCl. - Photosynthetica 44: 513-522, 2006.

Rathore, D., Agrawal, S.B., Singh, A.: Influence of supplemental UV-B radiation and minerals on biomass, pigments and yield of two cultivars of wheat (Triticum aestivum $\mathrm{L}$.). - Biotronics 32: 1-5, 2003.

Reddy, K.R., Vigaya, G.K., Duli, Z., Saliaja K., Wei, G.: Interactive effects of ultraviolet-B radiation and temperature on cotton physiology, growth, development and hyperspectral reflectance. - J. Photochem. Photobiol. 79: 416-427, 2004.

Roháček, K.: Chlorophyll fluorescence parameters: the definitions, photosynthetic meaning, and mutual relationships. - Photosynthetica 40: 13-29, 2002.

Rouhi, V., Samson, R., Lemeur, R., Van Damme, P.: Photosynthetic gas exchanges characteristics in three different almond species during drought stress and subsequent recovery. - Environ. Exp. Bot. 59: 117-129, 2007.

Scarascia-Mugnozza, G., De Angelis, P., Matteucci, G., Valentini, R.: Long term exposure to elevated $\mathrm{CO}_{2}$ in a natural Quercus ilex L. community: net photosynthesis and photochemical efficiency of PSII at different levels of water stress. - Plant Cell Environ. 19: 643-654, 1996.

Smith, J.L., Buritt, D.J., Bannister, P.: Shoot dry weight, chlorophyll and UV-B-absorbing compounds as indicators of plant's sensitivity to UV-B radiation. - Ann. Bot. 86: 10571063,2000

von Caemmerer, S., Farquhar, G.D.: Some relationships between the biochemistry of photosynthesis and gas exchange of leaves. - Planta 153: 376-387, 1981.

Wellburn, A.R.: The spectral determination of chlorophylls $a$ and $b$ as well as total carotenoids, using various solvents with spectrophotometers of different resolution. - J. Plant Physiol. 144: 307-313, 1994.

Xiaoqin, Y., Qing, L., Chao, H.: Growth and photosynthetic responses of Picea asperata seedlings to enhanced ultravioletB and to nitrogen supply. - Braz. J. Plant Physiol. 20:11-18, 2008. 